\title{
EHMTI-0132. Premonitory symptoms and migraine disability assessment (MIDAS) questionnaire
}

\author{
S Sretenovic, A Stanic, A Mitrovic \\ From 4th European Headache and Migraine Trust International Congress: EHMTIC 2014 \\ Copenhagen, Denmark. 18-21 September 2014
}

\section{Introduction}

Premonitory symptoms are symptoms which precede the migraine attack by $2-48 \mathrm{~h}$. Little attention has been paid to the variety of PS and how severely PS are affecting a patient's life.

\section{Aim}

Determine frequency of PS and investigation of a connection between PS and MIDAS scores.

\section{Methodology}

Unsponsored, prospective study lasted for 8 months. In order to be included in the study, subjects had to be above 18 years old, and meet IHS criteria for migraine (without or with aura). Patients have filled in a questionnaire, containing a total of 11 symptoms that have been described as possible migraine PS. Also they have done MIDAS test as a general measure of migraine severity.

\section{Results}

A total of 200 migraine patients ( $\mathrm{F}: \mathrm{M}=169: 31)$, mean age 40.6 years (range19-71) participated in this survey. 145 were diagnosed as having migraine without aura and 55 migraine with aura. 69 had a MIDAS score $\leq 10,54$ between 11 and 20 and 77 scored $\geq 21.73$ patients took different antimigraine preventive treatments. Most frequent individual premonitory symptoms were fatigue $(62.5 \%)$ and unhappiness $(62.0 \%)$ followed by stiff neck (58.5\%), photophobia (57.0\%), phonophobia (54.5\%), concentracion difficulties (50.5\%), nausea $(48.5 \%)$ and osmophobia(45.0\%), food craving (35.5\%), yawning (34.5\%) and water craving (30.0\%). Premonitory symptoms fatigue

Headache and Migraine Center "Migraine Center", University Clinical Center KBC "Zvezdara", Belgrade, Serbia

(c) 2014 Sretenovic et al; licensee Springer. This is an Open Access article distributed under the terms of the Creative Commons Attribution License (http://creativecommons.org/licenses/by/2.0), which permits unrestricted use, distribution, and reproduction in any medium, provided the original work is properly cited. and stiff neck were related with higher MIDAS scores $\left(\mathrm{r}^{2}=.041, \mathrm{~F}(4,4249), \mathrm{p}<.001\right)$.

\section{Conclusion}

Gender and age did not influence the frequency or the profile of PS. Taking prophylactic therapy for migraine was protective only for nausea. Fatigue and stiff neck were related with MIDAS scores, as they were more frequent, higher were the scores on the test.

No conflict of interest.

Published: 18 September 2014

doi:10.1186/1129-2377-15-S1-D60

Cite this article as: Sretenovic et al:: EHMTI-0132. Premonitory

symptoms and migraine disability assessment (MIDAS) questionnaire.

The Journal of Headache and Pain 2014 15(Suppl 1):D60.

Submit your manuscript to a SpringerOpen ${ }^{\bullet}$ journal and benefit from:

- Convenient online submission

- Rigorous peer review

- Immediate publication on acceptance

- Open access: articles freely available online

- High visibility within the field

- Retaining the copyright to your article

Submit your next manuscript at springeropen.com 